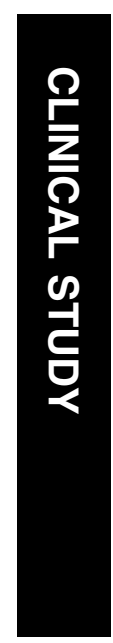

${ }^{1}$ Central Eye Service, Central Middlesex Hospital, North West London NHS Trust, London, UK

${ }^{2}$ Research and Development Department, Moorfields Eye Hospital NHS Foundation

Trust, London, UK

${ }^{3}$ Royal College of Ophthalmologists, London, UK

Correspondence: $\mathrm{V}$ Lee, Central Eye Service, Central Middlesex Hospital, Acton Lane, London NW10 7NS, UK

Tel: + 4402089637130 ;

Fax: + 4402089637158

E-mail: vickielee@

mac.com

Received: 30 November 2008

Accepted in revised form: 8 March 2009

Published online: 1 May 2009

Winner of the AMO Prize at the Annual Congress of the Royal College of Ophthalmologists, Liverpool, 2008.

\title{
Surveillance of traumatic optic neuropathy in the UK
}

\begin{abstract}
Aims The aim of this study is to provide epidemiological data on the incidence, aetiology, management, and visual outcome in traumatic optic neuropathy (TON) in the UK. Methods Patients with TON were identified prospectively by population-based active surveillance through the British Ophthalmic Surveillance Unit over a 2-year period with data obtained from an incident questionnaire and follow-up questionnaire sent to positive reporters.
\end{abstract}

Results Incident and follow-up data were available on 121 and $97(80 \%)$ patients, respectively. The minimum estimated incidence was 1.005 per million. Leading causes included falls $(25.6 \%)$, road traffic accidents (RTAs) (21.5\%), and assaults (20.7\%). The median age was 31 years. There were 95 (78.5\%) men. Presenting visual acuity (VA) was $6 / 60$ or worse in $85(70 \%)$ patients, with 43 patients $(36 \%)$ with no perception of light. Associated injuries included 47 (39\%) orbital wall fractures, 37 (31\%) closed globe injuries, $23(19 \%)$ ocular adnexal injuries, 23 (19\%) skull fractures, and 18 (16\%) intracranial bleeding. Sixty-five percent $(75 / 116)$ received no acute treatment and 35\% (41/116) received steroids and/or surgery. Of the treated group, $24 \%$ (8/ $33)$ and of the untreated group $20 \%(11 / 56)$ improved three lines or more of VA $(P=0.61)$. Prompt ophthalmic examination $(P=0.002)$, orbital fracture $(P=0.046)$, high Glasgow Coma Scale (GCS) score $(P=0.023)$, and poor initial VA $(P=0.009)$ were associated with increased likelihood of treatment. Poor initial VA $(P<0.001)$, orbital fracture $(P=0.004)$, and significant head injury $(P=0.038)$ were associated with poor visual outcome. Conclusions This study suggested that young men were at greatest risk of TON. We detected a trend towards conservative management of this condition in the UK. TON was associated
V Lee ${ }^{1}$, RL Ford ${ }^{1}$, W Xing ${ }^{2}$, C Bunce ${ }^{2}$ and B Foot ${ }^{3}$

with significant ocular, orbital, and head injuries that highlighted the need for multidisciplinary management.

Eye (2010) 24, 240-250; doi:10.1038/eye.2009.79; published online 1 May 2009

Keywords: TON; optic neuropathy; optic nerve injury; head injury; orbital fracture; BOSU

\section{Introduction}

Traumatic optic neuropathy (TON) is a rare cause of severe permanent visual impairment following injury. TON can be caused by sharp trauma (direct injury) damaging the optic nerve directly, but classically results from damage from transmitted forces following a concussive blow to the head or orbit (indirect injury). Typically, the initial clinical ophthalmic findings include decreased visual acuity (VA) and a relative afferent pupillary defect (RAPD) in unilateral or asymmetrically affected bilateral cases. Optic atrophy develops in the ensuing weeks or months.

Little is known about the epidemiology of this condition as most published reports in the medical literature consist of small noncomparative retrospective interventional case series. The management of TON remains controversial. There was a widespread trend to treat TON with varying doses of steroids, and megadose steroid treatment came into vogue due to extrapolation from the findings from the Second National Acute Spinal Cord Injury Study (NASCIS-II ${ }^{1}$ ). This approach has lost favour in recent years after the corticosteroid randomizationafter significant head injury $(\mathrm{CRASH})^{2}$ finding of adverse survival effect of megadose steroids in severe head injury.

There were reports in the TON case literature of 0-48\% $\%^{3-7}$ rate of spontaneous improvement, $44-82 \%{ }^{8,9}$ rate of improvement with varying 
doses of steroid treatment, and $37-71 \%^{10-13}$ rate of improvement with surgical optic nerve decompression. The 2001 International Optic Nerve Trauma Study (IONTS) ${ }_{1}^{14}$ the only prospective international observational study, and the recent TON Cochrane reviews ${ }^{15,16}$ did not recommend a standardized investigation or treatment protocol. To our knowledge, there have been no published data regarding the demographics of TON in the UK.

This study aimed to estimate the incidence of TON in the British Isles to determine national and regional patterns of presentation and ophthalmic referral, to obtain demographic data and to assess the types of injuries that lead to TON in the UK, to document the level of initial and final visual impairment and concurrent injuries, investigations and treatments in current use, and to determine the prognostic factors associated with a good or poor visual outcome.

\section{Materials and methods}

New cases of TON were ascertained prospectively with active surveillance through the British Ophthalmic Surveillance Unit (BOSU) over a 2-year period between November 2004 and November 2006.

The BOSU was established in 1997 under the auspices of the Royal College of Ophthalmologists to facilitate epidemiological research into rare eye conditions with significant public health or scientific importance. ${ }^{17}$ Investigators submitted proposals to the BOSU steering committee for approval of conditions to be surveyed. Monthly reporting cards were sent out to more than two UK-based ophthalmologists with clinical autonomy (1089 consultant ophthalmologists and associate specialists) requesting them to report all new patients seen in the previous month with the condition under surveillance or indicate nothing to report. The BOSU then informed the study investigators about the relevant reported cases. The study investigators then contacted the reporting ophthalmologists to seek all relevant clinical data. Appropriate approval for this study was granted by the Huntingdon Multi-Centre Research Ethics Committee.

TON was defined as any patient with new optic nerve dysfunction attributable to recent trauma in the absence of significant open globe trauma, with a RAPD in unilateral cases.

Between November 2004 and November 2006, every reporting ophthalmologist with a positive TON case notification to BOSU was sent a detailed incident questionnaire requesting data on the aetiology, presenting features and initial management of TON. A follow-up questionnaire was then sent 6 months later requesting information on subsequent management and outcome. Reminder letters were sent to all ophthalmologists who failed to return their questionnaire to improve the completeness of reporting.

To improve the accuracy of the estimate of incidence, duplicate reports in the absence of patient name were identified using hospital number, sex, and date of birth.

Data were recorded in a Microsoft Access database and analysed using Stata version 9 (StataCorp LP, TX, USA). VA data were collected in Snellen and analysed as an ordinal variable. $\chi^{2}$-Test/Fisher's exact test assesses evidence of association between categorical variables. The Wilcoxon rank-sum test was used to assess evidence of a difference between treatment status, final VA status dichotomized as 6/60, and ordinal variables such as VA and Glasgow Coma Scale (GCS) score.

\section{Results}

Over the 2-year study period, 205 reports of possible cases were received by BOSU, from all regions of the UK. Incident questionnaires were returned by 165 (80\%), of which 44 had to be excluded (7 were found to be clerical errors, 2 reports pertained to injuries first presenting before November 2004, 12 were duplicate reports, 12 were misdiagnoses, and in 11 cases no details could be recalled by the reporting ophthalmologist). The 'misdiagnoses' were cases initially suspected to be TON after an injury with an equivocal RAPD who were subsequently found to have alternate diagnoses. If duplicates, reporting errors, and misdiagnoses were excluded, clinical data were obtained from 121 of a possible 172 valid cases (70\%). Follow-up data were available on 97 of 121 possible patients (80\%). These response rates were similar to those achieved in previous BOSU active surveillance studies. Median (interquartile range, IQR) follow-up was 120 days (54-205 days) with follow-up duration recorded for 95 patients. Eighteen (18.9\%) patients had less than 30 days, $45(66.3 \%)$ had between 30 and 180 days, and 32 (33.7\%) had over 180 days of follow-up.

The reported incidence of TON in this study was 1.005 per million population (60.5/60.2095 million). The population of under $18 \mathrm{~s}$ in mid-2005 was 13.189 per million, as there were 26 cases of TON in the age group reported over 2 years, so the reported incidence was 0.9857 per million population.

\section{Patient demographics and presentation patterns}

Patient characteristics, referral patterns, and aetiology of injuries

Ninety-five $(79 \%)$ patients were men. The median (IQR) age at time of injury was $31(18,49)$ years, and $21 \%(26 /$ 121) were under 18 (Table 1 ). Seven patients (5.8\%) had bilateral TON. Eighty-two $(71 \%)$ patients were seen by an 
Table 1 Demographic and clinical characteristics

\begin{tabular}{lccc}
\hline Characteristics & $\begin{array}{c}\text { Number of } \\
\text { patients } \\
(\mathrm{N}=121)\end{array}$ & $\begin{array}{c}\text { Percentages } \\
\text { (col. } \%)\end{array}$ & IONTS \\
\hline Age, Median (IQR) & $31(18,49)$ & NA & \\
Age $<18$ & 26 & 21.5 & 34,18 (mean, SD) \\
Age $\geqslant 18$ & 95 & 78.5 & \\
Gender & & & \\
Male, $N$ & & & \\
Female, $N$ & 95 & 78.5 & $85 \%$ \\
& 26 & 21.5 & \\
Eye of injury & & & \\
Left & & & \\
Right & 54 & 44.6 & \\
Both & 60 & 49.6 & \\
& 7 & 5.8 \\
Injury type, $N$ & & & \\
RTA & & 21.5 & \\
Assault & 26 & 20.7 \\
Fall & 25 & 25.6 \\
Other & 31 & 0.8 \\
Data missing & 38 & \\
& 1 &
\end{tabular}

GCS, N

$\begin{array}{lrrc}>12 & 53 & 43.7 & \begin{array}{c}\text { Loss of } \\ \text { consciousness }\end{array} \\ 9-12 & 6 & 5.0 & \text { Yes }=34 \% \\ <9 & 10 & 8.3 & \text { No }=29 \% \\ \text { Data missing } & 52 & 43.0 & \text { Unknown }=13 \%\end{array}$

Category of ocular injury

External soft tissue

injury

Anterior segment

Posterior segment

Multiple

None

23

19.0

$12 \quad 9.9$

119.1

$14 \quad 11.6$

$61 \quad 50.4$

Orbital fracture

Simple $\quad 18$

$\begin{array}{lll}\text { Complex } & 29 & 24.0\end{array}$

None $\quad 72 \quad 59.5$

Data missing

$2 \quad 1.6$

Skull fracture and/or intracranial bleeding $\begin{array}{lll}\text { Skull fracture } & 9 & 7.4\end{array}$

Intracranial $\quad 4 \quad 3.3$

bleeding

Skull fracture and/ $\quad 14 \quad 11.6$

or intracranial

bleeding

None

$94 \quad 77.7$

Baseline VA

Unable to assess $\quad 3 \quad 2.5$

NPL

2.5
35.5

8.3

12.4

$\mathrm{HM}$

$6 / 60$ to $\mathrm{CF}$

$6 / 18-6 / 36$

$6 / 12$ and better
$2 \%$

$40 \%$

$10 \%$

$13 \%$

$16 \%$

$9 \%$

$10 \%$
Table 1 (Continued)

\begin{tabular}{|c|c|c|c|}
\hline Characteristics & $\begin{array}{c}\text { Number of } \\
\text { patients } \\
(\mathrm{N}=121)\end{array}$ & $\begin{array}{c}\text { Percentages } \\
\text { (col. \%) }\end{array}$ & IONTS \\
\hline \multicolumn{4}{|l|}{ Referral source } \\
\hline $\begin{array}{l}\text { Accident and } \\
\text { emergency }\end{array}$ & 52 & 43.0 & \\
\hline Neurosurgery & 13 & 10.7 & \\
\hline Maxillofacial & 13 & 10.7 & \\
\hline Ophthalmologists & 8 & 6.6 & \\
\hline GP & 12 & 9.9 & \\
\hline $\begin{array}{l}\text { More than one } \\
\text { source }\end{array}$ & 4 & 3.3 & \\
\hline Other & 17 & 14 & \\
\hline Data missing & 2 & 1.6 & \\
\hline \multicolumn{4}{|l|}{ Colour vision } \\
\hline Yes & 42 & 34.7 & \\
\hline No & 58 & 47.9 & \\
\hline Unable to assess & 21 & 17.4 & \\
\hline \multicolumn{4}{|l|}{ Visual field test } \\
\hline Confrontation & 28 & 23.1 & \\
\hline Humphrey's & 22 & 18.2 & \\
\hline Goldman & 11 & 9.1 & \\
\hline $\begin{array}{l}\text { More than one } \\
\text { method }\end{array}$ & 2 & 1.7 & \\
\hline Other & 1 & 0.8 & \\
\hline Not performed & 57 & 47.1 & \\
\hline \multicolumn{4}{|l|}{ Results of VF } \\
\hline Altitudinal & 9 & 7.4 & \\
\hline Central scotoma & 3 & 2.5 & \\
\hline Hemianopia & 7 & 5.8 & \\
\hline Total field loss & 20 & 16.5 & \\
\hline Other & 20 & 16.5 & \\
\hline Data missing & 5 & 4.1 & \\
\hline Not performed & 57 & 47.1 & \\
\hline \multicolumn{4}{|l|}{ Investigations } \\
\hline X-ray & 31 & 25.6 & \\
\hline $\mathrm{CT}$ & 90 & 74.3 & \\
\hline MRI & 32 & 26.4 & \\
\hline Ultrasound & 7 & 5.8 & \\
\hline $\begin{array}{l}\text { (More than one } \\
\text { invest) }\end{array}$ & 45 & 37.2 & \\
\hline None & 13 & 10.7 & \\
\hline \multicolumn{4}{|l|}{ Treatment } \\
\hline Steroids & 29 & 24 & $64 \%$ \\
\hline Surgery & 10 & 8.3 & \\
\hline Steroids and surgery & 2 & 1.7 & $33 \%$ OND \\
\hline None & 75 & 62 & $6.7 \%$ \\
\hline Data missing & 5 & 4.1 & \\
\hline
\end{tabular}

Abbreviations: CF, count fingers; GCS, Glasgow Coma Scale; GP, General Practice; HM, hand movements; IQR, interquartile range; NPL, no perception of light; OND, optic nerve decompression; PL, perception of light; VA, visual acuity; VF, visual field.

ophthalmologist within 3 days of presentation. Fifty-two (44\%) patients were referred from Accident and Emergency, 13 (11\%) from Neurology and Neurosurgery, 


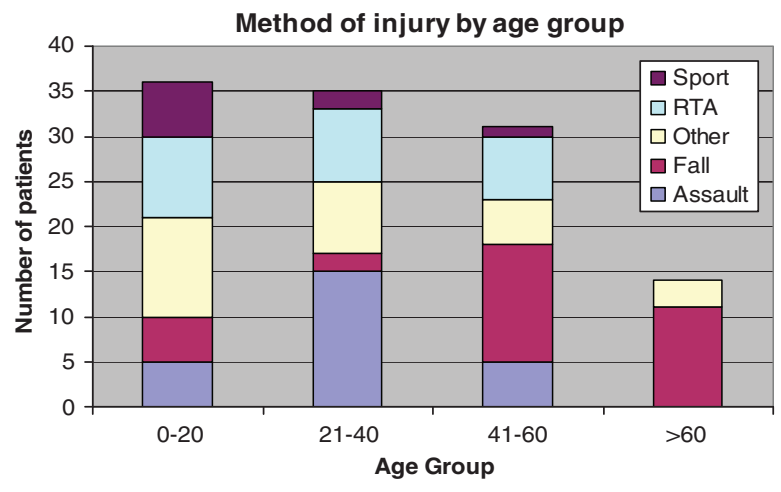

Figure 1 Method of injury by age group.

$13(11 \%)$ from Oral and Maxillofacial surgery, 12 (10\%) from General Practice, and 17 (14\%) from other sources. Only $8(7 \%)$ of patients presented directly to ophthalmologists. The most common causes of injury were the following: $26 \%$ (31/121) from falls, $21 \%$ (26/ 121) from road traffic accidents (RTAs), $21 \%(25 / 121)$ from assaults, and $8 \%(10 / 121)$ from sport.

Miscellaneous other causes included injury from falling objects, gardening accidents, and a terrorist bomb. When examining the causes by age group, sport, RTAs, and assaults were proportionately more common in the under- 60 age group and falls predominated in the more elderly cohort (Figure 1).

\section{Visual function at presentation}

VA was $6 / 60$ or worse in $85(70 \%)$ of patients at presentation, with 43 patients (36\%) with no perception of light (NPL) in the affected eye. Only $10(8.3 \%)$ patients presented with VA of $6 / 12$ or better; in these cases, the diagnosis was based on the presence of a RAPD and a visual field defect. Colour vision data were recorded for $42(35 \%)$ patients at presentation, of whom $32(76 \%)$ scored 12 or fewer plates on a standard 17-plate Ishihara test. None of these patients were known to have preexisting defects in colour vision, and all scored normally with the uninjured eye if unilaterally affected. Twentyone $(17 \%)$ of patients were recorded as unable to perform a colour vision test. At least one type of visual field testing was attempted in $64(53 \%)$ of patients (Table 1$)$.

\section{Ocular injury}

Patients with open globe trauma were excluded from this study due to the potential difficulty inherent in assessing these patients' optic nerve function at presentation, but $31 \%(37 / 121)$ of the patients with TON had an associated closed globe injury. Twelve $(10 \%)$ patients had anterior segment injury, $11(9 \%)$ had posterior segment injury, and $14(12 \%)$ had a combination of the above. Twenty-three patients (19\%) sustained ocular adnexal injury involving the eyelid and/or extraocular muscle(s) and/or orbital foreign body.

\section{Orbital injuries}

Forty-seven (39\%) patients had orbital wall fractures, 18 had 'simple' fractures (of the floor, medial, and/or lateral walls), and 29 had 'complex' fractures also involving the roof and/or orbital rims including $6(5 \%)$ patients with optic canal fractures.

\section{Head injury}

GCS score at presentation was recorded for $69(57 \%)$ patients, of whom $53(77 \%)$ with GCS >12, 6 (9\%) with GCS 9-12, and 10 (14\%) with GCS <9. ${ }^{18}$ Twenty-seven $(23 \%)$ had skull fractures and/or intracranial bleeding.

\section{Bilateral optic nerve injury}

There were three women and four men with bilateral optic nerve injury. Three were caused by RTAs, one from a parachute accident, one from a fall, one from a head injury during an epileptic seizure, and one unknown cause. Four patients presented with VA NPL in both eyes. The remaining three patients were asymmetrically affected with VA of NPL 1/60 and 6/18 in their worse affected eye and HM 6/9 (with colour vision loss) and 6/ 12 (with field loss) in the better eye. (For these three we have considered the worse affected eye to be the study eye for purposes of data interpretation.) Five patients had skull fractures and intracranial injuries, suggesting a high incidence of serious head trauma associated with the bilateral cases. Four of the seven had complex orbital fractures including an optic canal fracture. Two of those presenting with bilateral NPL remained NPL by 6 months follow-up and the patient with CF right and NPL left was unchanged at 2 months follow-up. One patient who presented with VA of 6/12 right and 6/18 left and a bitemporal field defect from chiasmal injury recovered to $6 / 5$ in each eye after 3 months.

\section{Radiological investigations}

Forty-five patients (37\%) had multiple and 13 (11\%) had no radiological investigations. Optic canal fractures were detected in six, retro-orbital haemorrhage in five, and optic nerve intrasheath haemorrhage in two patients (Table 1). 


\section{Treatment}

Treatment status was available on 116 patients (Table 2). $75(65 \%)$ had no acute treatment and $41(35 \%)$ received treatment: 29 (25\%) had steroid treatment alone, $10(9 \%)$ had surgery, and 2 patients had both steroids and surgery. The types of steroid used included intravenous dexamethasone, intravenous methylprednisolone, and oral prednisolone and at varying dosages. Surgical treatment included drainage of retrobulbar haematoma (2), orbital fracture repair (6), optic nerve decompression (2), and evacuation of orbital foreign body (2). The Wilcoxon rank-sum test showed that there was evidence of a difference in baseline VA between patients who did and did not receive treatment; presenting VA in patients who had treatment than patients who had no treatment $(P=0.009)$. Thirty-seven $(44 \%)$ of patients who visited the ophthalmologists within 7 days of their injury were treated compared to 4 (13\%) of patients of those who first saw an ophthalmologist after 7 or more days $(P=0.002)$ There was evidence too that the presence of an orbital fracture was associated with treatment: $48 \%$ of patients with orbital fractures had treatment compared with $29 \%$ of those who did not $(P=0.046)$. Also patients who had a higher GCS score were more likely to receive treatment than those with lower score $(P=0.023)$.

\section{Visual outcome}

VA outcome (Figure 2) data were available in 35 of the 41 treated patients and 58 of the 75 untreated patients. Of the treated group, 8 (24\%) and of the untreated group 11 (20\%) improved three lines or more of VA. Using Fisher's exact test by dichotomizing patients into these two groups showed no association between treatment and visual outcome $(P=0.61)$. However there was strong evidence of an association between final VA and baseline VA $(P<0.001)$, significant head injury with skull fracture and/or intracranial bleeding $(P=0.038)$ and orbital fracture $(P=0.004)$ (Tables 3 and 4$)$.

\section{Discussion}

TON was first described by Hippocrates ${ }^{19}$ over 2000 years ago and remains an uncommon but severe cause of visual loss after blunt periocular trauma.

\section{Anatomy and pathophysiology}

The transmitted deformative stress most commonly affects the intracanalicular segment ${ }^{20,21}$ of the optic nerve where the dural sheath is tightly adherent to the orbital periosteum, and may be associated with optic canal and sphenoidal fractures. ${ }^{22}$ The next most common site of injury is the intracranial portion of the optic nerve close to the falciform dural fold, ${ }^{23}$ which may be the anatomical basis of most bilateral TON injuries.

The pathophysiology is multifactorial and the current hypothesis consists of irreversible immediate primary injury of direct axonal disruption, and potentially reversible secondary injury from ischaemia and activation of apoptotic cascades in the retinal ganglion cells. Most research into neuroprotection strategies is currently based on limiting damage from secondary injury. $^{24}$

\section{Clinical features}

TON can be unilateral or bilateral, and is characterized by the presence of a RAPD except in cases of symmetric, bilateral TON. The impairment of VA can be variable but is classically severe.

The visual loss is usually immediate but could be delayed. In cases where colour vision and visual field testing could be performed, there is often impairment of colour vision and variable visual field defects. The initial ocular examination is typically normal in posterior nerve injuries, but in anterior nerve injuries there may be associated optic disc swelling and retinal haemorrhages.

Classically optic atrophy develops in the weeks following the injury.

\section{Epidemiology}

The incidence of TON following head trauma in published case series varied between 0.7 and $2.5 \% .^{25,26}$ Previous epidemiological data derived from multiple retrospective case series and the IONTS have indicated male preponderance, young age, and leading causes from RTAs, falls, and assaults in both adult ${ }^{27}$ and paediatric ${ }^{28,29}$ cohorts.

Despite our study utilizing an effective active surveillance methodology that received high levels of support from the UK ophthalmologists, ${ }^{30,31}$ there remained a certain level of underascertainment and consequently we are reporting minimum estimates of incidence rates. The overall response rate of the BOSU reporting cards for the surveillance period was $77 \%$, whereas this did not relate directly to the level of ascertainment it did indicate that it was unlikely that all cases were reported. Furthermore, additional cases would exist within the 51 reports for which no further details were obtained. Previous surveillance studies with the BOSU had indicated ascertainment rates between 75 and $100 \%, 32$ and it would be acceptable to consider that ascertainment for this study to be similar and that the incidence might vary accordingly. Examination of the 
Table 2 Demographic and baseline characteristics by treatment group

\begin{tabular}{|c|c|c|c|c|}
\hline \multirow[t]{2}{*}{ Characteristics } & \multicolumn{2}{|c|}{ Treatment received } & \multirow[t]{2}{*}{ Total $(\mathrm{N}=116)$} & \multirow[t]{2}{*}{$\mathrm{P}$} \\
\hline & Yes $($ Row \%) $\mathrm{N}=41$ & No $($ Row \%) $\mathrm{N}=75$ & & \\
\hline GCS, N & Missing $=17$ & Missing $=33$ & Missing $=50^{\mathrm{a}}$ & \\
\hline$\geqslant 13$ & $22(44)$ & $28(56)$ & 50 & \\
\hline $9-12$ & $1(17)$ & $5(83)$ & 6 & \\
\hline$\leqslant 8$ & $1(10)$ & $9(90)$ & 10 & $0.023^{\mathrm{b}}$ \\
\hline \multicolumn{5}{|l|}{ Gender } \\
\hline Male & $33(36)$ & $58(64)$ & 91 & \\
\hline Female & $8(32)$ & $17(68)$ & 25 & $0.815^{c}$ \\
\hline Method of injury & & Missing $=1$ & Missing $=1^{\mathrm{a}}$ & \\
\hline RTA & $11(42)$ & $15(58)$ & 26 & \\
\hline Fall & $11(41)$ & $16(59)$ & 27 & $0.680^{c}$ \\
\hline Assaults & $8(32)$ & $17(68)$ & 25 & \\
\hline Other & $11(30)$ & $26(70)$ & 37 & \\
\hline \multicolumn{5}{|l|}{ Age } \\
\hline$<18$ & $11(44)$ & $14(56)$ & 25 & \\
\hline$\geqslant 18$ & $30(33)$ & $61(67)$ & 91 & $0.349^{c}$ \\
\hline \multicolumn{5}{|l|}{ Ocular injury } \\
\hline Anterior segment & $6(50)$ & $6(50)$ & 12 & \\
\hline Posterior segment & $4(36)$ & $7(64)$ & 11 & \\
\hline Multiple & $5(38)$ & $8(62)$ & 13 & $0.743^{c}$ \\
\hline External & $8(38)$ & $13(62)$ & 21 & \\
\hline None & $18(31)$ & $41(69)$ & 59 & \\
\hline Orbital fracture & & Missing $=2$ & Missing $=2^{a}$ & \\
\hline Yes & $21(48)$ & $23(52)$ & 44 & $0.046^{\mathrm{c}}$ \\
\hline No & $20(29)$ & $50(71)$ & 70 & \\
\hline \multicolumn{5}{|c|}{ Skull fracture/intracranial bleeding } \\
\hline Yes & $8(30)$ & $19(70)$ & 27 & $0.646^{\mathrm{c}}$ \\
\hline No & $33(37)$ & $56(63)$ & 89 & \\
\hline \multicolumn{5}{|l|}{ Optic canal } \\
\hline Yes & $3(50)$ & $3(50)$ & 6 & $0.664^{\mathrm{c}}$ \\
\hline No & $38(35)$ & $72(65)$ & 110 & \\
\hline \multicolumn{5}{|l|}{ Lateral of TON } \\
\hline Bilateral & $1(14)$ & $6(86)$ & 7 & \\
\hline Unilateral & $40(37)$ & $69(63)$ & 109 & $0.419^{c}$ \\
\hline \multicolumn{5}{|c|}{ Delay for ophthalmologists } \\
\hline$<7$ days & $37(44)$ & $48(56)$ & 85 & \\
\hline$\geqslant 7$ days & $4(13)$ & $27(87)$ & 31 & $0.002^{c}$ \\
\hline \multicolumn{5}{|l|}{ Baseline VA, N (col. \%) } \\
\hline Unable to assess ${ }^{\mathrm{a}}$ & $1(2.4)$ & $2(2.7)$ & $3^{\mathrm{a}}$ & \\
\hline NPL & $18(43.9)$ & $24(32)$ & 42 & $0.009^{\mathrm{b}}$ \\
\hline PL & $6(14.6)$ & $2(2.7)$ & 8 & \\
\hline $\mathrm{HM}$ & $7(17.1)$ & $8(10.7)$ & 15 & \\
\hline $\mathrm{CF}$ to $6 / 60$ & $4(9.7)$ & $12(16)$ & 16 & \\
\hline $6 / 36-6 / 18$ & $3(7.3)$ & $19(25.3)$ & 22 & \\
\hline $6 / 12$ and better & $2(4.9)$ & $8(10.7)$ & 10 & \\
\hline
\end{tabular}

Abbreviations: CF, count fingers; GCS, Glasgow Coma Scale; HM, hand movements; NPL, no perception of light; PL, perception of light; RTA, road traffic accidents; TON, traumatic optic neuropathy; VA, visual acuity.

a Excluded from the test.

bMann-Whitney test.

c $\chi^{2}$-test/Fisher's exact test. 


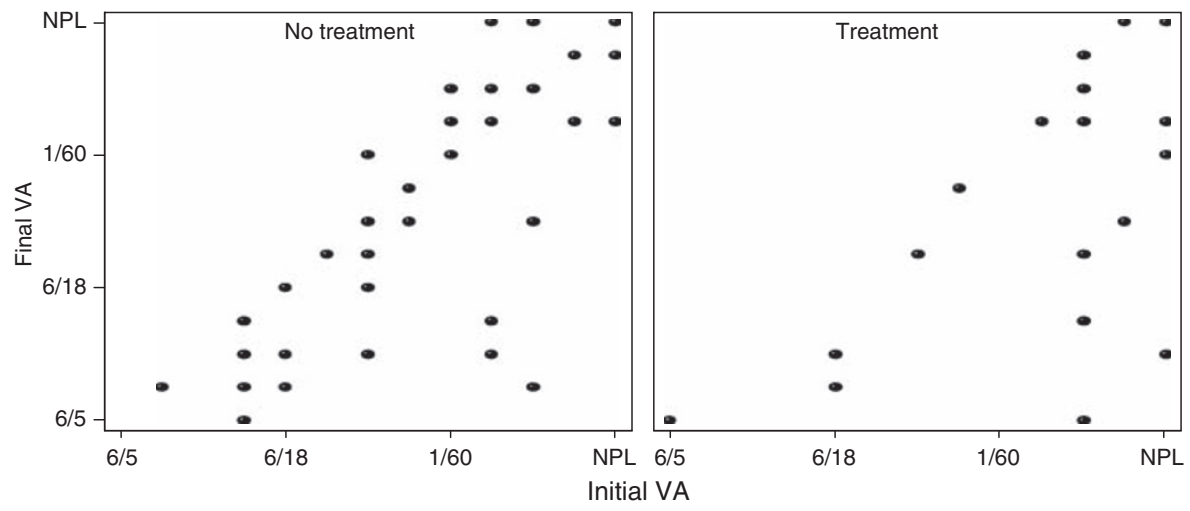

Figure 2 Scatter plot of final VA and pre-VA by treatment group.

reporting patterns and the data set did not reveal any obvious inconsistencies and as such it was appropriate to assume that any underascertainment was due to random rather than systematic error and would not unduly affect the representative nature of the study population.

We tabulated key data items to allow for easy comparison to the IONTS findings as the IONTS methodology and design had the most similarities to our study. There were however significant differences - the IONTS originated as a randomized interventional trial that was altered to an observational interventional trial due to difficulties in patient recruitment. The IONTS had strict inclusion criteria, with no paediatric patients and a tendency to actively treat patients with steroids and/or surgery. Although there was a variety of steroid dosing regimes used in the IONTS, all surgical treatment entailed optic nerve decompression. The nature of the BOSU surveillance study meant that there was great diversity of treatments used. Therefore, we have divided our patients into two groups - no treatment and treatment (encompassing both steroids and surgery). This also reflected the tendency for conservative treatment in our cohort to ensure there were adequate numbers of patients in each group for meaningful comparison.

Our study was the first to use a validated populationbased surveillance to elucidate the epidemiology of TON. We estimated the minimum incidence of this condition to be 1.005 per million and confirmed the major at risk group to be young men. We also found that children were affected with similar incidence to adults. This study also confirmed the leading causes of TON to be falls, assaults, and RTAs (together accounting for $68 \%$ of all cases). Moreover, there was a significant level of associated head, orbital, and ocular injury that had not been previously documented and highlighted the need for multidisciplinary management.

\section{Treatment}

The main treatment options in current use for TON were observation alone, ie conservative management; systemic steroids; surgery, eg decompression of the optic canal, optic nerve sheath fenestration, evacuation of compressive orbital haematoma; and a combination of steroids and surgery.

\section{Conservative treatment}

We detected a trend for conservative management of TON among the UK ophthalmologists (65\%). Although one-fifth of patients appeared to spontaneously improve with no acute treatment, a significant number were left with severe visual impairment in their affected eye.

\section{Steroid treatment}

Moderate doses of systemic steroids have been used to treat TON since the $1980 \mathrm{~s}^{33,34}$ based on laboratory findings of its anti-oxidant and free radical inhibitory properties. $^{35}$

There was no universal agreement as to the type, dosage, and timing of steroid treatment in TON. The steroid regimes in the TON literature ranged from daily doses of $<100$ to $5400 \mathrm{mg}$ (megadose) per day. ${ }^{36}$ The vogue for using megadose steroids started with the NASCIS-II, which was a multicentre, randomized, double-blind, placebo-controlled trial. NASCIS-II found that patients who received steroids within $8 \mathrm{~h}$ of their injury had significantly improved neurological functions compared to those in the placebo group or those who were treated after $8 \mathrm{~h}$. The NASCIS-III appeared to confirm the benefit of early megadose steroid treatment. However, these findings remained controversial due to accusations of post hoc subgroup analysis, ${ }^{37}$ and questions remained about the validity of direct 
Table 3 Demographic and baseline characteristics by final visual acuity

\begin{tabular}{|c|c|c|c|c|}
\hline \multirow[t]{2}{*}{ Characteristics } & \multicolumn{2}{|c|}{ Final BCVA } & \multirow[t]{2}{*}{ Total $\left(\mathrm{N}=97^{\mathrm{a}}\right)$} & \multirow[t]{2}{*}{$\mathrm{P}$} \\
\hline & Better than $6 / 60($ Row \%) $\mathrm{N}=34$ & $6 / 60 \&$ worse $($ Row \%) $\mathrm{N}=63$ & & \\
\hline GCS, N & Missing $=14$ & Missing $=27$ & Missing $=41^{\mathrm{b}}$ & \\
\hline$\geqslant 13$ & $13(30)$ & $30(70)$ & 43 & \\
\hline $9-12$ & $3(100)$ & 0 & 3 & 0.185 \\
\hline$\leqslant 8$ & $4(40)$ & $6(60)$ & 10 & \\
\hline \multicolumn{5}{|l|}{ Gender } \\
\hline Male & $26(33)$ & $52(67)$ & 78 & \\
\hline Female & $8(42)$ & $11(58)$ & 19 & $0.593^{c}$ \\
\hline Method of injury & & Missing $=1$ & Missing $=1^{\mathrm{b}}$ & \\
\hline RTA & $5(23)$ & $17(77)$ & 22 & \\
\hline Fall & $6(24)$ & $19(76)$ & 25 & $0.032^{\mathrm{c}}$ \\
\hline Assaults & $5(29)$ & $12(71)$ & 17 & \\
\hline Other & $18(56)$ & $14(44)$ & 32 & \\
\hline \multicolumn{5}{|l|}{ Age } \\
\hline$<18$ & $10(43)$ & $13(57)$ & 23 & \\
\hline$\geqslant 18$ & $24(32)$ & $50(68)$ & 74 & $0.453^{c}$ \\
\hline \multicolumn{5}{|l|}{ Ocular injury } \\
\hline Anterior segment & $4(40)$ & $6(60)$ & 10 & \\
\hline Posterior Segment & $3(33)$ & $6(67)$ & 9 & \\
\hline Multiple & $1(8)$ & $12(92)$ & 13 & $0.198^{c}$ \\
\hline External & $8(47)$ & $9(53)$ & 17 & \\
\hline None & $18(38)$ & $30(62)$ & 48 & \\
\hline Orbital fracture & & Missing $=1$ & Missing $=1^{\mathrm{b}}$ & \\
\hline Yes & $7(18)$ & $32(82)$ & 39 & $0.004^{\mathrm{c}}$ \\
\hline No & $27(47)$ & $30(53)$ & 57 & \\
\hline \multicolumn{5}{|c|}{ Skull fracture/intracranial bleeding } \\
\hline Yes & $3(15)$ & $17(85)$ & 20 & $0.038^{\mathrm{c}}$ \\
\hline No & $31(40)$ & $46(60)$ & 77 & \\
\hline \multicolumn{5}{|l|}{ Optic canal } \\
\hline Yes & 0 & $5(100)$ & 5 & $0.159^{c}$ \\
\hline No & $34(37)$ & $58(63)$ & 92 & \\
\hline \multicolumn{5}{|l|}{ Lateral of TON } \\
\hline Bilateral & 0 & $4(100)$ & 4 & \\
\hline Unilateral & $34(37)$ & $59(63)$ & 93 & $0.294^{c}$ \\
\hline Treatment & & Missing $=4$ & Missing $=4^{\mathrm{b}}$ & \\
\hline Steroids or/and surgery & $10(29)$ & $25(71)$ & 35 & \\
\hline No treatment & $24(41)$ & $34(59)$ & 58 & $0.269^{c}$ \\
\hline \multicolumn{5}{|l|}{ Delay for ophthalmologists } \\
\hline$<7$ days & $25(33)$ & $50(67)$ & 75 & \\
\hline$\geqslant 7$ days & $9(41)$ & $13(59)$ & 22 & $0.613^{c}$ \\
\hline \multicolumn{5}{|l|}{ Baseline VA, N } \\
\hline Unable to assess ${ }^{\mathrm{b}}$ & $1(33)$ & $2(67)$ & $3^{\mathrm{b}}$ & \\
\hline NPL & $1(3)$ & $35(97)$ & 36 & \\
\hline PL & $1(11)$ & $8(89)$ & 9 & \\
\hline $\mathrm{HM}$ & $6(46)$ & $7(54)$ & 13 & $0.000^{\mathrm{d}}$ \\
\hline $\mathrm{CF}$ to $6 / 60$ & $3(23)$ & $10(77)$ & 13 & \\
\hline $6 / 36-6 / 18$ & $15(94)$ & $1(6)$ & 16 & \\
\hline $6 / 12$ and better & $7(100)$ & 0 & 7 & \\
\hline
\end{tabular}

Abbreviations: CF, count fingers; GCS, Glasgow Coma Scale; HM, hand movements; NPL, no perception of light; PL, perception of light; RTA, road traffic accidents; TON, traumatic optic neuropathy; VA, visual acuity.

${ }^{a}$ Follow-up data not available on 24 patients.

${ }^{b}$ Excluded from the test.

c $\chi^{2}$-test/Fisher's exact test.

${ }^{\mathrm{d}}$ Mann-Whitney test. 
Table 4 Final vision improvement $\geqslant 3$ lines by treatment group

\begin{tabular}{lcc}
\hline & $\begin{array}{c}\text { Treatment } \\
\text { (col. \%) }\end{array}$ & $\begin{array}{c}\text { No treatment } \\
\text { (col. \%) }\end{array}$ \\
\hline Total $\left(N=113^{\text {a }}\right)$ & $N=33$ & $N=56$ \\
$\geqslant 3$ lines improvement & $8(24)$ & $11(20)$ \\
Baseline NPL, PL, HM & $N=31$ & $N=34$ \\
$\geqslant 3$ lines improvement & $7(23)$ & $4(12)$ \\
Baseline CF or better & $N=9$ & $N=39$ \\
$\geqslant 3$ lines improvement & $1(11)$ & $7(18)$ \\
\hline
\end{tabular}

Abbreviations: CF, count fingers; HM, hand movements; NPL, no perception of light; PL, perception of light.

a Eighty-nine patients had information on treatment, baseline VA, and final VA.

extrapolation to TON treatment. In light of the recent laboratory research on animal optic nerves ${ }^{38-40}$ and CRASH findings of adverse survival implications associated with megadose steroid treatment in severe head injuries, a recent Cochrane review recommended that steroids should not be routinely given at all in head injuries, ${ }^{41}$ reflecting the current consensus of TON management

\section{Surgical treatment}

Various case series showed benefit from optic canal decompression surgery, ${ }^{11-13}$ particularly in the presence of optic canal fracture with an impinging bony fragment. Others ${ }^{42}$ recommended optic nerve fenestration in the cases of intrasheath haemorrhage detected on MRI scanning. ${ }^{43}$

\section{Conclusions}

Our data showed that there was an association between presenting VA and whether or not patients received active treatment, those with worse VA being more likely to receive treatment. Prompt ophthalmic examination and presence of orbital fractures also increased the likelihood of patients receiving active treatment. Similar to the IONTS study, we found the initial VA to be predictive of the final VA, with a trend for better improvement in VA in patients without orbital fractures noted in previous publications. ${ }^{44,45}$ Significant head injury also appeared to be an adverse prognostic factor for visual outcome.

The proportion of patients with VA that improved three lines or more was similar in the treated $(24 \%)$ and untreated $(20 \%)$ group $(P=0.61)$. However, suggesting there was no treatment benefit with regard to final VA needed to be interpreted with caution due to the difference in baseline variables of the treated and untreated cohorts and the diversity of treatments used. This was an observational study not a randomized controlled trial so the treating physicians were free to tailor treatments to their patients, as they deemed appropriate. The study also revealed that significant numbers of patients with TON had associated ocular, orbital, and head injuries and hence highlighted the need for multidisciplinary management.

In concordance with the IONTS, we also recommend that treatment should be tailored for the individual patient. All patients should receive a thorough ophthalmic, adnexal, and neurological examination. Fine-section CT imaging should be routinely used in the acute management to identify concurrent injuries and the presence of optic canal fractures. There appeared to be little evidence to suggest benefit of steroid treatment for isolated optic nerve injury where visual loss is immediate. Surgical treatment should be directed by the radiological findings. Orbital haematomas causing optic nerve compression should be acutely evacuated, and where there is a bony fragment impinging on the nerve from a optic canal fracture then endoscopic optic nerve decompression should be considered, and similarly optic nerve fenestration in the case of intrasheath haemorrhage. We recognize that effectiveness of most of the surgical interventions may be within a critical time frame and in practice there may be delays in presentation and varying availability of local expertise and patients should be counselled that the prognosis for visual improvement is guarded especially in cases with poor presenting VA.

\section{Acknowledgements}

We are grateful for the support of the British Ophthalmic Surveillance Unit. The work was supported by a grant from the Central Middlesex Hospital Eye Clinic Fund. We thank the following ophthalmologists who have reported cases to this study: Mr J Acheson, Miss D AhKine, Mr S Ahmed, Mr RW Allchin, Mr ED Allen, Mr S Armstrong, Mr S Ataullah, Mr HR Atta, Mr HF Bacon, Mr R Bates, Miss K Belfer, Mr PD Black, Mrs T Blamires, Mr CR Bentley, Mr AK Brahma, Mr F Bremner, Mr MC Briggs, Mr MA Burdon, Miss SEP Burgess, Mr R Caesar, Mr IG Calder, Mr A Cassels-Brown, Mr JKT Chan, Mr PR Chaudhuri, Mr S Chawdhury, Mrs JK Chhina, Mr JR Clarke, Mr MD Cole, Mr A Coombes, Dr M Cooper, Mr R Dagres, Mr RB Dapling, Mr K Davey, Mr DV De Alwis, Mr JA Dunne, Miss O Earley, Miss BE Enoch, Dr J Ellis, Mr D Etchells, Mr MG Falcon, Mrs V Ferguson, Mr J Ferris, Mr DW Flanagan, Professor JV Forrester, Mr PD Fox, Mr DG Frazer, Mr LB Freeman, Mrs H Gaston, Dr ND George, Mr RA Gibson, Mr JT Gillow, Mr RHB Grey, Dr DJ Grierson, Mr PG Griffiths, Mr C Hammond, Miss J 
Harcourt, Mr R Haslett, Mr JM Hayward, Dr DJ Huggan, Mr C Illingworth, Mr A Jacks, Mr JSH Jacob, Miss CA Jones, Mr A Kamal, Mr WSS Karwatowski, Mr VV Kayarkar, Mr J Keenan, Miss G Larkin, Mr N Lee, Mr NP Litvin, Mr M Logendran, Mr V Long, Mr J Luck, Mr G Mackingtosh, Dr JR Mackinnon, Dr DC Manfield, Miss R Manners, Miss DC Mather, Mr BK McLeod, Mr JE Morgan, Mr SJ Morgan, Mr AP Moriarty, Mr CD Morsman, Mrs CE Morton, Mr G Naylor, Dr J Olsen, Mr V Pai, Dr S Patterson-Brown, Dr R Paul, Mr JC Pauw, Mrs I Pepper, Mr W Poon, Mr M Potts, Mr AP Plumb, Mr A Quinn, Mr C Rene, Mr P Riordan-Eva, Dr STD Roxburgh, Mr NJ Sarkies, Mr S Scotcher, Mr C Scott, Dr JA Scott, Mr RAH Scott, Mr PR Simcock, Mr DL Smerdon, Mr R Smith, Mr L Stevenson, Mr G Sturrock, Miss S Vickers, Mr AN Tadros, Mr A Tekriwal, Mr DM Tole, Mr A Toufeeq, Mr JM Twomey, Mr V Vampali, Mr AJ Vivian, Mr IMJ Wearne, Ms S Webber, Mr ST White, Dr Whittle, and Mr YF Yang.

\section{References}

1 Bracken MB, Shepard MJ, Collins WF, Holford TR, Baskin DS, Eisenberg HM et al. A randomized controlled trial of methylprednisolone or naloxone in the treatment of acute spinal cord injury. Results of the second national acute spinal cord injury study. N Engl J Med 1990; 322: 1405-1411.

2 Edwards P, Arango M, Balica L, Cottingham R, El-Sayed H, Farrell B et al. Final results of MRC CRASH, a randomised placebo-controlled trial of intravenous corticosteroid in adults with head injury-outcomes at 6 months. Lancet 2005; 365: 1957-1959.

3 Chou PI, Sadun AA, Chen YC, Su WY, Lin SZ, Lee CC. Clinical experiences in the management of traumatic optic neuropathy. Neuro-ophthalmology 1996; 16: 325-336.

4 Lessell S. Indirect optic nerve trauma. Arch Ophthalmol 1989; 107: 382-386.

5 Seiff SR. High dose corticosteroids for treatment of vision loss due to indirect injury to the optic nerve. Ophthalmic Surg 1990; 21(6): 389-395.

6 Edmund J, Gotfredsen E. Unilateral optic atrophy following head injury. Acta Ophthalmologica 1963; 41: 693-697.

7 Hughes B. Indirect injury of the optic nerves and chiasma. Bull Johns Hopkins Hosp 1962; 111: 98-126.

8 Spoor TC, Hartel WC, Lensink DB, Wilkinson MJ. Treatment of traumatic optic neuropathy with corticosteroids. Am J Ophthalmol 1990; 110: 665-669.

9 Mauriello JA, DeLuca J, Krieger A, Schulder M, Frohman L. Management of traumatic optic neuropathy - a study of 23 patients. Br J Ophthalmol 1992; 76: 349-352.

10 Rajiniganth MG, Gupta AK, Gupta A, Bapuraj JR. Traumatic optic neuropathy: visual outcome following combined therapy protocol. Arch Otolaryngol Head Neck Surg 2003; 129: 1203-1206.

11 Yang WG, Chen CT, Tsay PK, de Villa GH, Tsai YJ, Chen YR. Outcome for traumatic optic neuropathy - surgical vs nonsurgical treatment. Anna Plast Surg 2004; 52: 36-42.

12 Levin LA, Joseph MP, Rizzo JF, Lessell S. Optic canal decompression in indirect optic nerve trauma. Ophthalmology 1994; 101: 566-569.
13 Fujitani T, Inoue $\mathrm{K}$, Takahashi $\mathrm{T}$, Ikushima $\mathrm{K}$, Asai T. Indirect traumatic optic neuropathy: visual outcome of operative and non-operative cases. Jpn J Ophthalmol 1986; 30: 125-134.

14 Levin LA, Beck RW, Joseph MP, Seiff S, Kraker R. The treatment of traumatic optic neuropathy: the International Optic Nerve Trauma Study. Ophthalmology 1999; 106: 1268-1277.

15 Yu-Wai-Man P, Griffith P. Steroids for traumatic optic neuropathy. Cochrane Database Syst Rev 2007, Issue 4. Art. No.: CD006032.

16 Yu-Wai-Man P, Griffiths PG. Surgery for traumatic optic neuropathy. Cochrane Database Syst Rev 2005, Issue 4.Art. No.: CD005024.

17 Rahi JS, Edelsten C. The British Ophthalmological Surveillance Unit: the study of uncommon ophthalmic disorders made easier. Eye 2003; 17: 9-15.

18 Teasdale G, Jennett B. Assessment of coma and impaired consciousness. A practical scale. Lancet 1974; 2: 81-84.

19 Chadwick J, Mann WN. The Medical Works of Hippocrates: A New Translation from the Original Greek. Charles C Thomas: Springfield, IL, 1950, pp 260.

20 Anderson RL, Panje WR, Gross CE. Optic-nerve blindness following blunt forehead trauma. Ophthalmology 1982; 89: 445-455.

21 Gross CE, DeKock JR, Panje WR, Hershkowitz N, Newman $\mathrm{J}$. Evidence for orbital deformation that may contribute to monocular blindness following minor frontal head trauma. J Neurosurg 1981; 55: 963-966.

22 Seiff SR. High dose corticosteroids for treatment of vision loss due to indirect injury to the optic nerve. Ophthalmic Surg 1990; 21: 389-395.

23 Crompton MR. Visual lesions in closed head injury. Brain 1970; 93: 785-792.

24 Osborne NN, Chidlow G, Layton CJ, Wood JP, Casson RJ, Melena J. Optic nerve and neuroprotection strategies. Eye 2004; 18: 1075-1084.

25 al-Qurainy IA, Stassen LF, Dutton GN, Moos KF, el-Attar A. The characteristics of midfacial fractures and the association with ocular injury: a prospective study. Br J Oral Maxillofac Surg 1991; 29: 291-301.

26 Nau HE, Gerhard L, Foerster M, Nahser HC, Reinhardt V, Joka T. Optic nerve trauma: clinical, electrophysiological and histological remarks. Acta Neurochirurgica 1987; 89: 16-27.

27 Steinsapir KD, Goldberg RA. Traumatic optic neuropathies. In: Miller NR, Newman NJ (eds). Walsh and Hoyt's Clinical Neuro-Ophthalmology. Williams and Wilkins: Baltimore, MD, 1998, pp 715-739.

28 Mahapatra AK, Tandon DA. Traumatic optic neuropathy in children: a prospective study. Pediatr Neurosurg 1993; 19: 34-39.

29 Goldenberg-Cohen N, Miller NR, Repka MX. Traumatic optic neuropathy in children and adolescents. J AAPOS 2004; 8: 20-27.

30 Thacker SB, Redmond S, Berkelman RL. A controlled trial of disease surveillance strategies. Am J Prev Med 1986; 2: 345-350.

31 Vogt RL, LaRue D, Klaucke DN, Jillison DA. Comparison of an active and passive surveillance system of primary care providers for hepatitis, measles, rubella, and salmonellosis in Vermont. Am J Public Health 1983; 73: 795-797.

32 Foot B, Stanford M, Rahi J, Thompson J. The British Ophthalmological Surveillance unit: an evaluation of the first 3 years. Eye 2003; 17: 9-15.

33 Braughler JM, Hall ED, Means ED, Waters TR, Anderson DK. Evaluation of an intensive methylprednisolone sodium 
succinate dosing regimen in experimental spinal cord injury. J Neurosurg 1987; 67: 102-105.

34 Hall ED, Braughler JM. Corticosteroid therapy in experimental cord injury. J Neurosurg 1984; 61: 805-806.

35 Hall ED. The neuroprotective pharmacology of methylprednisolone. J Neurosurg 1992; 76(1): 13-22.

36 Steinsapir KD, Goldberg RA. Traumatic optic neuropathy: a critical update. Comp Ophthalmol Update 2005; 6(1): 11-21.

37 Spencer MT, Bazarian JJ. Evidence-based emergency medicine/systematic review abstract - are corticosteroids effective in traumatic spinal cord injury. Ann Emerg Med 2003; 41: 410-413.

38 Steinsapir KD, Goldberg RA, Sinha S, Hovda DA. Methylprednisolone exacerbates axonal loss following optic nerve trauma in rats. Restor Neurol Neurosci 2000; 17: 157-163.

39 Ohlsson M, Westerlund U, Langmoen IA, Svensson M. Methylprednisolone treatment does not influence axonal regeneration or degeneration following optic nerve injury in the adult rat. J Neuro-ophthalmol 2004; 24: 11-18.
40 Diem R, Hobom M, Maier K, Weissert R, Storch MK, Meyer $\mathrm{R}$ et al. Methylprednisolone increases neuronal apoptosis during autoimmune CNS inflammation by inhibition of an endogenous neuroprotective pathway. J Neurosci 2003; 23: 6993-7000.

41 Alderson P, Roberts I. Corticosteroids for acute traumatic brain injury. Cochrane Database Syst Rev 2005, Issue 1. Art. No.: CD000196.

42 Levin LA, Baker RS. Management of traumatic optic neuropathy. J Neuro-ophthalmol 2003; 23: 72-75.

43 Takehara S, Tanaka T, Uemura K, Shinohara Y, Yamamoto T, Tokuyama T et al. Optic nerve injury demonstrated by MRI with STIR sequences. Neuroradiology 1994; 36(7): 512-514.

44 Cook MW, Levin LA, Joseph MP, Pinczower EF. Traumatic optic neuropathy. A meta-analysis. Arch Otolaryngol Head Neck Surg 1996; 122: 389-392.

45 Wang BH, Robertson BC, Girotto JA, Liem A, Miller NR, Iliff $\mathrm{N}$ et al. Traumatic optic neuropathy: a review of 61 patients. Plast Reconstr Surg 2001; 107: 1655-1664. 